\title{
EFFECT OF MOBILE PHONE RADIATION ON ADRENAL GLAND OF MALE ALBINO RATS
}

\author{
Shalini Gupta1, Shilpi Jain², Satyam Khare², Prateek Gautam¹
}

1. Department of Anatomy, BRD Medical College and Hospital, Gorakhpur, U.P. 2. Department of Anatomy, Subharti Medical College, Meerut, U.P.

\begin{abstract}
Introduction: The tremendous growth in telecommunication world has increased the number of mobile phone users to many folds. The benefits of cell phones are just half the picture. The other half may be a darker one. The main aim of this study is to observe the effect of electromagnetic radiation being emitted by mobile phones on adrenal gland microanatomy and the hormones released by the gland on male albino rats.

Materials and methods: Forty-two male albino rats of Spargue-Dawley species were divided into two equal groups. The experimental group rats were exposed to mobile phone radiation operating at 900 $\mathrm{MHz}$ while the control group rats were not. At the end of every two months, seven rats were sacrificed to analyse histological and hormonal changes.

Results: No changes were seen at the cellular level of the adrenal glands even after six months of radiation exposure. Hormonal assay showed a variation in the cortisol levels of the rats but the changes were within normal range.

Conclusions: Lack of appreciable changes in the cellular morphology and hormonal levels even after six months of radiation exposure signify that the adrenal glands are not affected by exposure to mobile phones.

Keywords: Mobile Phone, Albino Rats, Adrenal Gland, Cortisol.

\section{INTRODUCTION}

GSM stands for Global System for Mobile communications. It is a digital mobile telephone system used in most parts of the world. GSM uses a time division multiple access which

enables more people to communicate simultaneously with a station. According to GSM world, there are now more than 3 billion GSM mobile phone users worldwide with China referenced as the largest single GSM market with more than 370 million users [1].
\end{abstract}

Address for Correspondence:

Dr Shalini Gupta, Assistant Professor, Department of Anatomy, BRD Medical College, Gorakhpur, U.P., India. 273013 Mob: 8874014992, Email - guptashalini22@yahoo.com

Date of Receiving: 12 August 2020

Date of Acceptance: 07 September 2020

0970-1842/Copyright (C) JAS 2020 
Tremendous growth in the use of cell phones has led to more demand for land to site telecommunication base stations and related infrastructures. However, as cell phone usage skyrockets, the concern over potential health risks rises as well. This is a consequence of the radiation emitted by handsets and base stations that receive and transmit the signals. Although some scientists and researchers across the globe claim there is no adverse effect from the use of mobile phones and its base stations, others in different countries in different laboratories, are finding disturbing results that point to far greater health implications than anyone is ready for [2].

Having suggested the potentially harmful effects of EMW radiation on some biological systems, recent studies have dealt with the concerns regarding the safety of radio frequency (RF)-EMW exposure. For example, the microwaves emitted by mobile phones have been linked to several genetic defects [3-5].

Microwave radiation may induce chromosomal instability and may lead to increased risk of cancer as suggested by Sykes et al. in 2001 and 2002, by Mashevich et al. in 2003 and Agarwal in 2007 [6-8]. Scientific researches have highlighted some extremely hazardous effects of exposure to radiation emitted from cell phones on the human body. These effects range from those at the molecular level manifested as an increase in single and double strand DNA breakages [9], change in Ornithine decarboxylase activity [10], increased risk of brain tumors [11] to disruption of learned behavior, dysaesthesia, etc. [12] and an increase in chick embryo mortality [13].
So according to the above effects of microwave radiation, the risk on adrenal gland as an essential organ becomes most important in the study of this issue [14]. Results from epidemiological studies indicate that cell phone radiation power density even below the standard level can cause symptoms such as headache, heat sensation in the ears, memory loss and fatigue and show significant relationship with the duration of call / time of the day [15-20].

Regarding the endocrine system, the sensitivity of pineal gland, pituitary gland, adrenal gland and thyroid gland as well as of the endocrine pancreas, testicles and ovaries to EMWs have been investigated [21]. Various papers were published on different endocrine glands but adrenal gland was the least explored. Hence, considering the lack of data on the effects of GSM mobile phone-induced electromagnetic fields on the adrenal gland and cortisol hormone in humans, the aim of the present study was to assess the potential alterations of cortisol hormones and microanatomy of adrenal gland after exposure to microwave radiation emitted by mobile phones.

\section{MATERIALS AND METHODS}

VENUE: The entire study was conducted in the department of Anatomy, BRD Medical College, Gorakhpur in collaboration with the department of Pharmacology of the institute. STUDY MODEL: Forty-two male albino rats of Spargue -Dawley species were chosen for the experiment. INCLUSION CRITERIA: A) Male rats $B)$ Knowingly disease-free C) Age about 1.5 months-2 months D) Weight about 100-150 gms. 
PROCUREMENT: All the rats were procured from Central Drug Research Institute, Lucknow along with their health certificates. After the procurement of the rats they underwent the process of acclimatization for one week during which they were fed with recommended pellet diet and water ad libidum. Twelve-hourly day and night cycle was maintained with appropriated temperature and humidity. Ethical clearance was taken from institutional animal ethical committee and experiment was performed as per the recommended guidelines. GROUP DIVISION: The rats were divided into 2 groups having 21 rats each. Group A was the control group and Group B was the experimental group. Both the groups of rats were given exactly the same conditions and environment. The only difference was in the fact that Group-B rats were exposed to mobile phone radiation while Group A rats were not. In fact, the control group of rats were kept in different room in order to avoid any exposure to radiation. RADIATION SET UP: Plastic cages normally available for rat housing were used and the base of the cage was floored with thermocol sheet. A slot was cut at the corner of the cage in thermocol sheet to adjust the mobile phone in it. The cage was partitioned using a wooden plank in order to restrict the movement of rats during the experiment. A GSM model mobile phone with frequency bandwidth of 900 $\mathrm{MHz}$ and power of 2 watt with a SAR value of $0.38 \mathrm{~W} / \mathrm{Kg}$ was used to carry out the experiment. When the experiment was 'ON', a call was made from another cell phone on the mobile phone being kept inside the cage and the call was received in order to make the phone on answering mode for the next one hour. During this period, the rats remained in touch with the mobile phone and were receiving the radiations just like humans [22-25]. The entire experiment was repeated for 6 months and at the end of every two months, seven rats from both the group were scarified and the tissue of adrenal gland and their blood sample were collected for analysis. HORMONAL ANALYSIS: After the sacrifice of rats from both the groups, the blood sample of each rat was collected directly from the heart and was sent immediately to the lab for hormonal analysis of cortisol. Reports were collected and the data obtained was tabulated and analysed. HISTOLOGICAL ANALYSIS: Just after the sacrifice of rats the adrenal gland was procured and was kept in $10 \%$ formalin solution. The tissues collected were processed using routine tissue processing technique used for Hematoxylin and Eosin staining methods. Slides were prepared and visualized under microscopes.

\section{RESULTS}

\section{A. MICROSCOPIC ANALYSIS}

\section{CONTROL GROUP: (Fig. 1-a)}

- The interior of the adrenal gland was divided into outer cortex and inner medulla.

- Cortex further exhibited three concentric zones: - zona glomerulosa, zona fasiculata and zona reticularis.

- Zona glomerulosa was a thin zone interior to the adrenal gland capsule. It consisted of cells arranged in small clumps.

- Zona fasiculata was intermediate and the thickest zone of the adrenal cortex. This zone exhibited vertical columns of one cell thickness adjacent to straight capillaries. It 
consisted of pale staining cells due to increased lipid droplets.

- Zona reticularis was the innermost zone that was adjacent to the medulla. The cells here were arranged in cords or clumps.

- Medulla lied toward the centre of the gland, cells here were also arranged in small cords and were secretory in nature (epinephrine and nor-epinephrine).

- Medulla contained a lot of capillary network.

\section{EXPERIMENTAL GROUP:}

At the time of $2^{\text {nd }}$ month of sacrifice: (Fig. 1-b)

- No appreciable changes were observed after $2^{\text {nd }}$ month of radiation doses to the rats.

- The microscopic picture observed was more or less similar to the control group of rats.

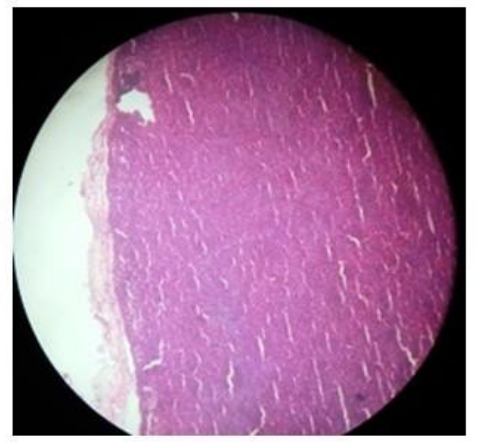

(a)

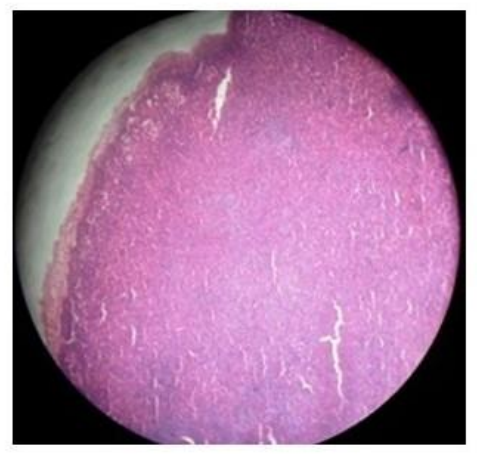

(c)
At the time of $4^{\text {th }}$ month of sacrifice: (Fig. 1-c)

- No appreciable changes were observed after $4^{\text {th }}$ month of radiation doses to the rats.

At the time of $6^{\text {th }}$ month of sacrifice: (Fig. 1-d)

- No appreciable changes were observed after $6^{\text {th }}$ month of radiation doses to the rats.

- Lack of changes at the cellular level in adrenal gland even after the exposure of 6 months was a clear indication of the fact that whatever other changes in parameter observed were not because of stress. This fact was very well supported by the level of corticosteroid hormones which showed no rise during the experiment.

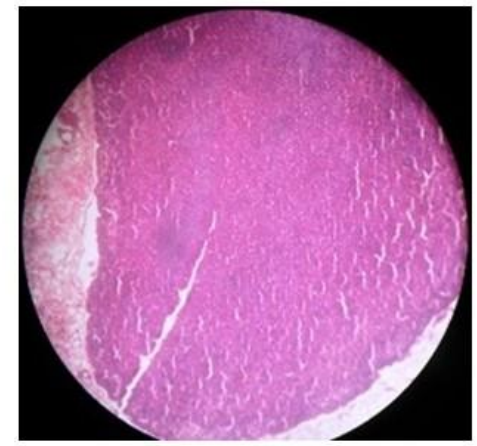

(b)

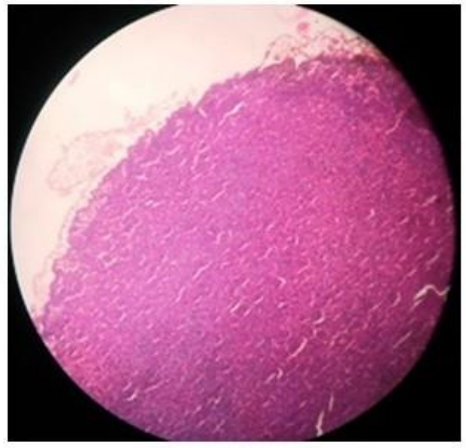

(d)

Fig. 1. Microscopic picture of Adrenal gland (40x) (a) Control group, (b) Experimental group at 2 months (c) Experimental group at 4 months and (d) Experimental group at 6 months 
B. .HORMONAL ANALYSIS

- The analysis done from the data obtained for the cortisol level suggested that there were no changes occurring in the level of cortisol throughout the experiment.

- After $2^{\text {nd }}$ month of experiment, the tables and bar diagram showed that there was variation in the level of cortisol in both the groups of rats but the data obtained from both the groups remained within the normal range. (Fig. 2).

- The same result was obtained from the data analysis after four months (Fig. 3) and after six months of the experiment (Fig. 4).

- Whether it was the control or the experimental group of rats, the level of cortisol remained within the limits of normal range.

- This data also indicated that throughout the experiment there was no increase in the stress of rats.

- Hence the changes being observed at any level were not due to any stress to the rats.

\section{DISCUSSION}

Various researches have suggested that electromagnetic radiation emitted from base stations and cell phones have destructive effects on tissues in two ways. To begin with, warm impacts happen by means of increment in bodily warmth by electromagnetic vitality, which is consumed by the body. Second, nonwarm impacts show up as changes in cerebrum capacities and headaches [26].

Studies concentrating on the impacts of EMR radiated by mobile phones have yielded dubious outcomes. Past investigations have detailed that radiofrequency waves produced especially by the third era mobile phones may affect the immunological status, sensory system, hematological status, cardiovascular capacities, urinary framework, typical development and genes [27], cells [28], tissues [29], organs and embryonic improvement [30]. Alongside this, EMR may likewise prompt DNA damage.

However, on the other hand there are studies in the literature reporting that cell phones do not have an effect on blood-brain barrier, testes, sperm morphology, semineferous tubules and Leydig cells of the rats and do not cause a significant change in mean fetal heart rate [31].

Similarly, in comprehensive studies conducted in the USA and Denmark, it was reported that cell phone use was not associated with increased risk of brain tumor [32], direct genotoxic, mutagenic or cytotoxic effects [33]. To date such studies reporting hazardous as well as non-hazardous effects have used different experimental animal models like rats [34], mice [35], chick [36], etc.

In our study, we investigated the effect of mobile phone radiation operating at $900 \mathrm{MHz}$ upon one important organ, that is the adrenal gland, over a period of 6 months and found that there was not much appreciable change occurring in the histology or physiology of the adrenal gland. However, Sima and Imam et al found alterations in the cortisol level of rats after exposure for 6 hours daily for 8 weeks. They also reported that the zona fasciculata layer of adrenal cortex eventually thickened following mobile RF radiation. The quantity of cells in 


\begin{tabular}{|c|c|c|c|c|}
\hline & \multicolumn{2}{|c|}{$\mathbf{1}^{\text {st }}$ day } & \multicolumn{2}{c|}{$\mathbf{2}^{\text {nd }}$ month } \\
\hline R.no & Control & Experimental & Control & Experimental \\
\hline 1 & 0.29 & 1.42 & 0.22 & 1.29 \\
\hline 2 & 0.31 & 1.38 & 0.26 & 0.87 \\
\hline 3 & 0.44 & 0.76 & 0.34 & 0.44 \\
\hline 4 & 2.01 & 0.82 & 1.44 & 0.57 \\
\hline 5 & 1.46 & 0.97 & 1.32 & 0.78 \\
\hline 6 & 0.91 & 2.10 & 0.72 & 1.88 \\
\hline 7 & 1.78 & 1.21 & 1.66 & 1.09 \\
\hline Mean & 1.028571 & 1.237143 & 0.85142857 & 0.988571 \\
\hline SD & 0.72299 & 0.46046 & 0.61197572 & 0.488106 \\
\hline P & 0.5278 & & 0.6676 & \\
\hline value & & & & \\
\hline
\end{tabular}

Table 1. Comparison of Cortisol in Experimental and Control Group of rats after $2^{\text {nd }}$ month

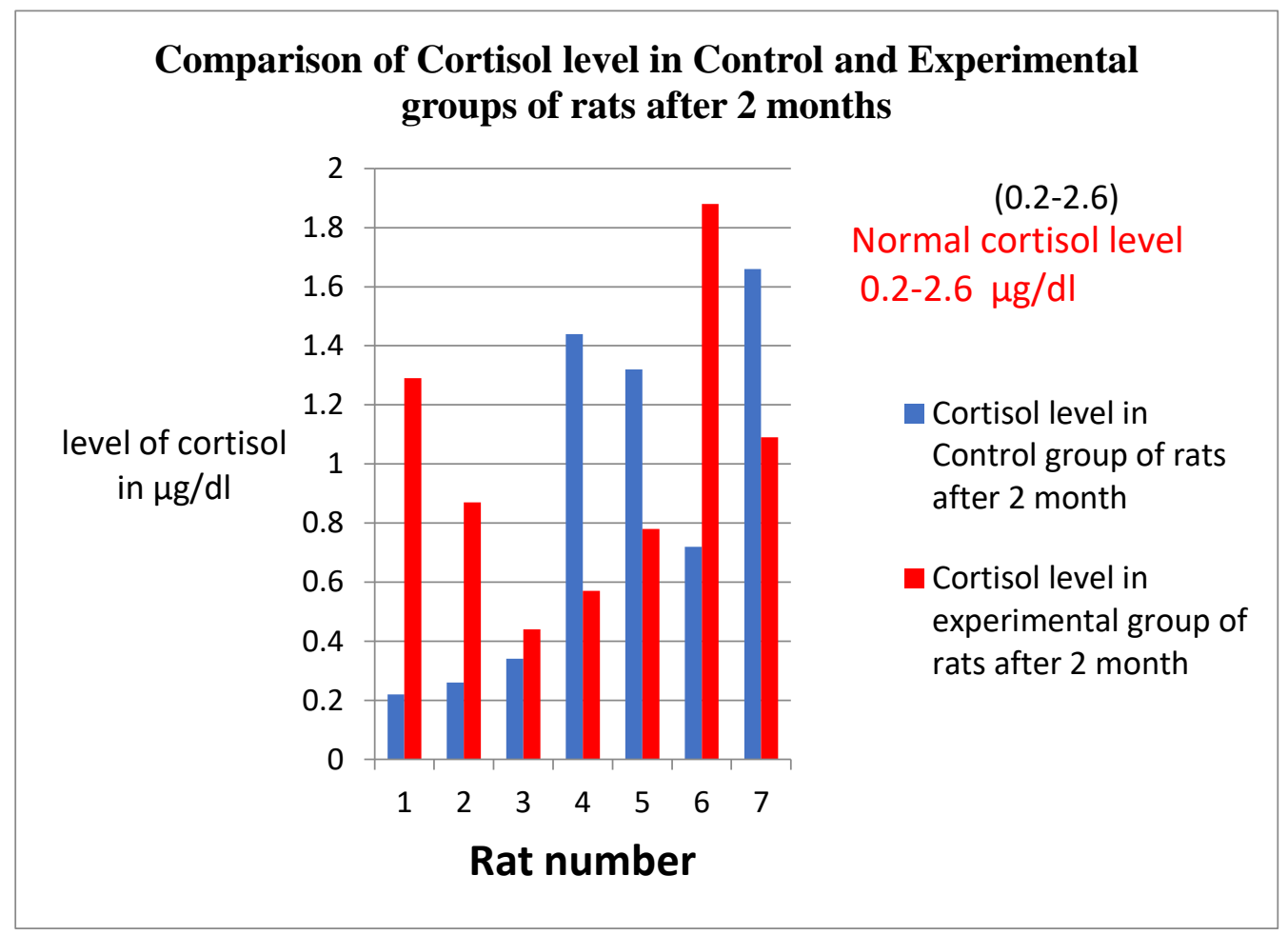

Fig. 2. Comparison of Cortisol in Experimental and Control groups of rats after $2^{\text {nd }}$ month 


\begin{tabular}{|c|c|c|c|c|}
\hline & \multicolumn{2}{|c|}{$1^{\text {st }}$ day } & \multicolumn{2}{c|}{ 4 $^{\text {th }}$ month } \\
\hline R.No & Control & Experimental & Control & Experimental \\
\hline 1 & 2.10 & 1.43 & 1.78 & 1.23 \\
\hline 2 & 2.20 & 1.92 & 2.01 & 1.65 \\
\hline 3 & 1.89 & 1.94 & 1.77 & 1.74 \\
\hline 4 & 1.32 & 2.56 & 0.76 & 2.00 \\
\hline 5 & 1.40 & 2.53 & 0.87 & 2.32 \\
\hline 6 & 1.23 & 1.38 & 1.02 & 1.09 \\
\hline 7 & 1.86 & 2.52 & 1.65 & 2.34 \\
\hline Mean & 1.714286 & 2.04 & 1.408571 & 1.76714286 \\
\hline S.D & 0.392762 & 0.512022 & 0.508312 & 0.49151854 \\
\hline Pvalue & & 0.1989 & & 0.1987 \\
\hline
\end{tabular}

Table 2. Comparison of Cortisol in Experimental and Control groups of rats after $4^{\text {th }}$ month

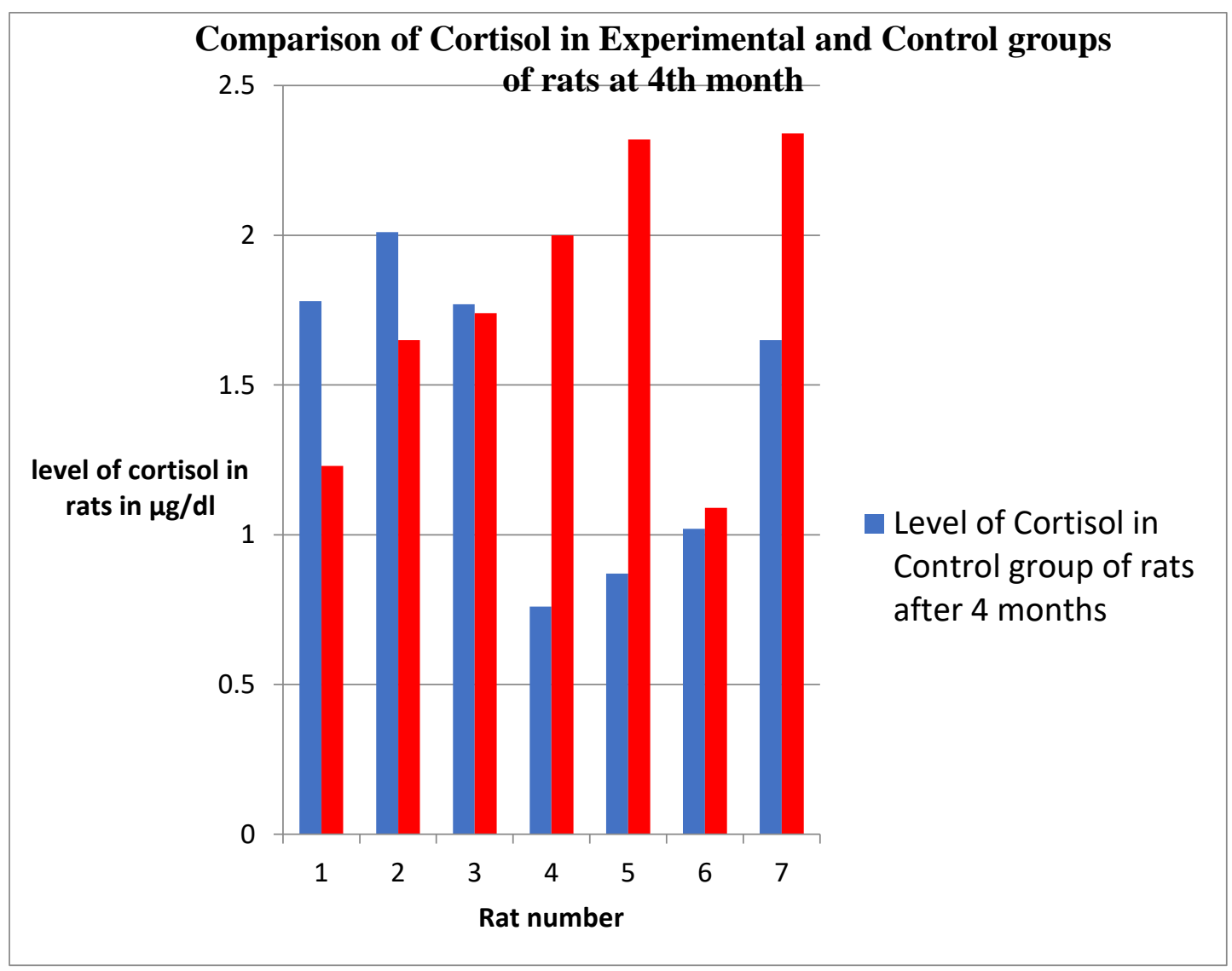

Fig. 3. Comparison of Cortisol in Experimental and Control groups of rats after $4^{\text {th }}$ month 


\begin{tabular}{|c|c|c|c|c|}
\hline \multicolumn{2}{|l|}{$1^{\text {st }}$ day } & \multicolumn{1}{l|}{ 4 $^{\text {th }}$ month } \\
\hline R.No & Control & Experimental & Control & Experimental \\
\hline 1 & 2.56 & 2.34 & 2.31 & 2.01 \\
\hline 2 & 2.39 & 2.56 & 2.12 & 2.34 \\
\hline 3 & 2.32 & 2.30 & 2.03 & 2.10 \\
\hline 4 & 2.09 & 1.12 & 1.67 & 0.98 \\
\hline 5 & 1.96 & 2.51 & 1.89 & 2.33 \\
\hline 6 & 1.81 & 2.48 & 1.65 & 2.08 \\
\hline 7 & 1.54 & 2.55 & 0.87 & 2.31 \\
\hline Mean & 2.095714 & 2.265714 & 1.791429 & 2.02142 \\
\hline S.D & 0.356224 & 0.515165 & 0.470334 & 0.478589 \\
\hline Pvalue & \multicolumn{2}{|l}{0.4811} & & 0.3780 \\
\hline
\end{tabular}

Table 3. Comparison of Cortisol in Experimental and Control groups of rats after $6^{\text {th }}$ month

\section{Comparison of Cortisol of Experimental and Control groups of rats after $6^{\text {th }}$ month}

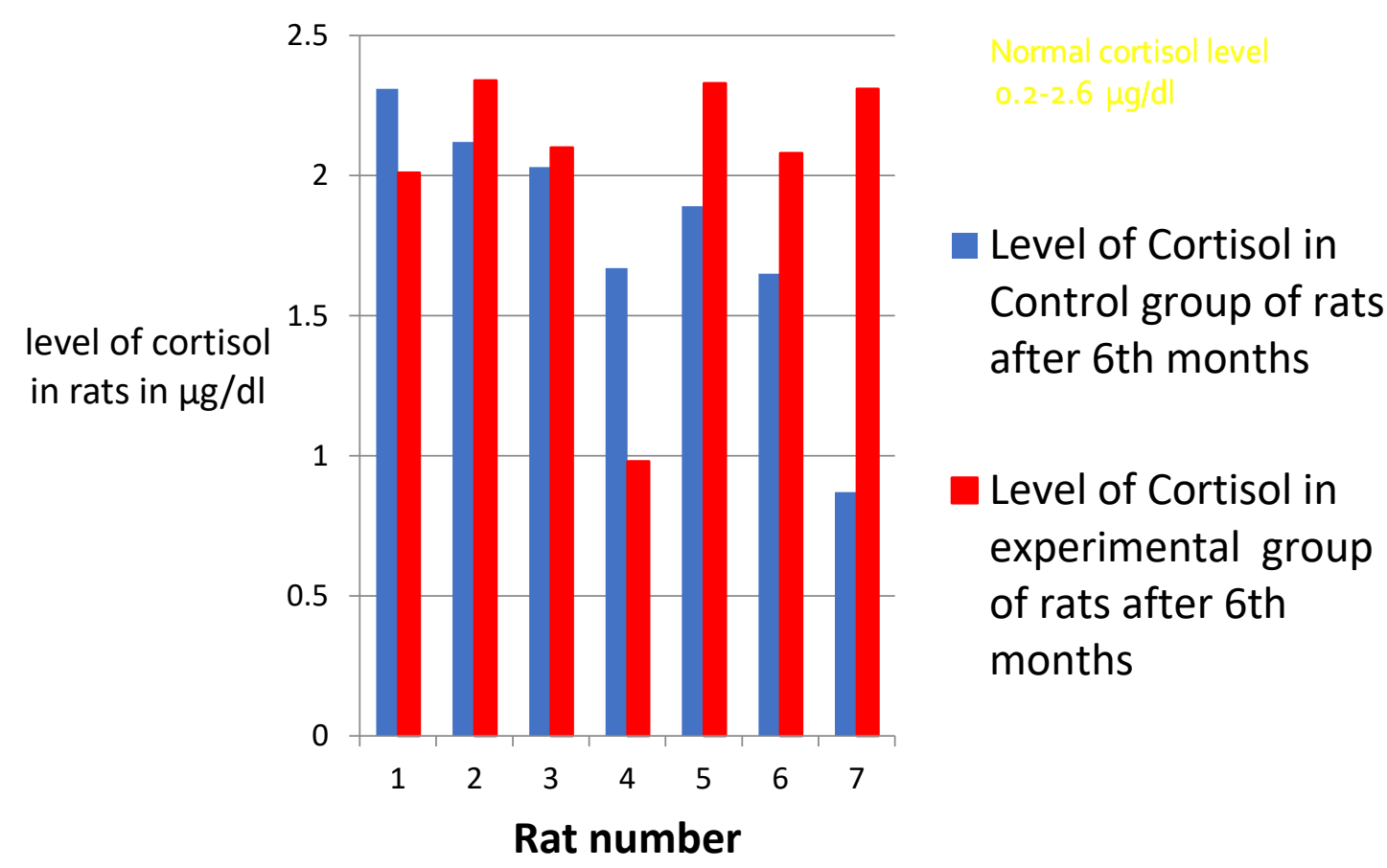

Fig. 4. Comparison of Cortisol in Experimental and Control groups of rats for $6^{\text {th }}$ month 
zona fasciculata stayed steady, in spite of the expanding phone size and edge during RF presentation.

Alteration in results may be due to the species of rats, their morphology, environmental conditions, amount and duration of exposure to radiation, etc. Any conclusive result to be quoted requires more extensive study with more parameters.

\section{CONCLUSION}

The results obtained from our experiment showed that even after an exposure of rats to mobile phone radiation for 6 months, there were no significant changes obtained in adrenal gland morphology at microscopic level and even the hormonal level. Though variation in the level of the hormone was very well reported but the data obtained after the analysis was all within the limit of normal range of cortisol level. This also proves that the rats were not stressed during the experiment and hence, any other parameter studied will have minimum chances of error due to stress factor.

\section{REFERENCES}

1. Friedhelm, H; (2002) "GSM and UMTS, the Creation of Global Mobile Communications", John Wiley and Sons, Inc., NY.

2. Gutierrez, D (2008): Mobile Phone Radiation to Unleash Epidemic of Brain Tumors, Natural News. www.naturalnew.com.

3. Pacini S., Ruggiero M., Sardi I., Aterini S., Gulisano F., Gulisano M., 2002. Exposure to global system for mobile communication
(GSM) cellular phone radiofrequency alters gene expression, proliferation, and morphology of human skin fibroblasts. Oncol. Res., 13, 19-24.

4. Aitken R., Bennetts L., Sawyer D., Wiklendt A., King B., 2005. Impact of radiofrequency electromagnetic radiation on DNA integrity in the male germline. Int. J. Androl., 28, 171179.

5. Tice RR., Hook GG., Donner M., McRee DI., Guy AW., 2002. Genotoxicity of radiofrequency signals. I. Investigation of DNA damage and micronuclei induction in cultured human blood cells. Bioelectromagnetics, 23, 113-126.

6. Sykes PJ., McCallum BD., Bangay MJ., Hooker AM., Morley AA., 2001. Effect of exposure to $900 \mathrm{MHz}$ radiofrequency radiation on intrachromosomal recombination in pKZ1 mice. Radiat. Res., 156, 495-502.

7. Mashevich M., Folkman D., Kesar A., Barbul A., Korenstein R., Jerby E., Avivi L., 2003. Exposure of human peripheral blood lymphocytes to electromagnetic fields associated with cellular phones leads to chromosomal instability. Bioelectromagnetics, 24, 82-90.

8. Agarwal A., 2007. Cell phones and male infertility: dissecting the relationship. Reprod. Biomed., 15, 266-270.

9. Lai $H$. and Singh N. P, Single and double strand DNA breaks in rat brain cells after exposure to radio frequency electromagnetic radiation. International Journal of Radiation I Biology 1996; 521. 
10.Penafiel,M., Litovitz,T., Krause,D., Desta,A, Mullins, J.M., Role of modulation on the effect of microwaves on ornithine decarboxylase activity in L929 cells, Bioelectromagnetics 1997; 18 : 132-141.

11. HardelL L, Nasman A, Pahlson A., Hallquist A. and Mild K.H, Use of cellular telephone \& the risk for brain tumours: A case control study. International Journal of I Oncology 1999;15:11.3.

12. Hocking B, Preliminary report: Symptoms associated with mobile phone use, Occup .med 1998; 48 (6) 357.

13.Magras I.N. and Xenos T.D, RF radiationinduced changes in the prenatal development of mice. Bioelectromagnetics 1997;18: 455-461.

14. Jadidi, M., M. Firouzabadi, A. Rashidipour, et al. 2005. Effects of acute exposure to radiation $950 \mathrm{MHz}$ cellular systems consolidation of spatial memory in rats, Journal of Semnan University of Medical Sciences, 6(4): 305-311.

15.Yioultsis, T.V., E.P. Kosmanias, T.T. Kosmidou, T.T. Zigiridis, N.V. Kantartzis, T.D. Xenos, et al. 2002. A comparative study of the biological effects of various mobile phone and wireless LAN antennas. IEEE Transaction on Magnetic, 38(2): 777-80.

16.Sandstrom, M., J. Wilen, G. Oftedal, M.K. Hansson, 2001. Mobile phone use and subject symptoms. Comparision of symptoms experienced by users of analogue and digital mobile phones. Occup Med., 51(1): 25-35.

17.Oftedal, G., J. Wilen, M. Sandstrom, K.H. Mild, 2000. Symptoms experienced in connection with mobile phone use. Occup Med., 50(4): 237-45.

18.Hocking, B., 1998. Preliminary report: Symptoms associated with mobile phone use. Occup Med, 48(6): 357-60.

19.Hocking, B., R. Westerman, 2001. Neurological abnormalities associated with CDMA exposure. Occup Med., 51(6): 410-3.

20. Hocking, B., R. Westerman, 2001. Neurological effects of radiofrequency radiation. Occup Med., 53: 123-7.

21.Stevens RG. Electric power use and breast cancer: a hypothesis. Am J Epidemiol 1987. Apr;125(4):556-561.

22. Löscher W, Mevissen M. Animal studies on the role of 50/60-Hertz magnetic fields in carcinogenesis. Life Sci1994;54(21):15311543 10.1016/0024-3205(94)90024-8.

23. Brainard GC, Kavet R, Kheifets LI. The relationship between electromagnetic field and light exposures to melatonin and breast cancer risk: a review of the relevant literature. J Pineal Res 1999. Mar;26(2):65100 10.1111/j.1600-079X.1999.tb00568.x.

24. Graham C, Cook MR, Gerkovich MM, Sastre A. Examination of the melatonin hypothesis in women exposed at night to EMF or bright light. Environ Health Perspect 2001 May;109(5):501-507 10.1289/ehp.01109501.

25. Ossenkopp KP, Koltek WT, Persinger MA. Prenatal exposure to an extremely low frequency-low intensity rotating magnetic field and increases in thyroid and testicle weight in rats. Dev Psychobiol 1972;5(3):27528510.1002/dev.4 20050312. 
26. Zagorskaya EA. Endocrine responses to low frequency electromagnetic fields of continuous and intermittent generation. Kosm Biol Aviakosm Med 1989;23:4-14.

27.Picazo ML, Miguel MP, Leyton V, Franco P, Varela L, Paniagua $\mathrm{R}$, et al. Long-term effects of ELF magnetic fields on the mouse testis and serum testosterone levels. Electro-Magnetobiol 1995;14:127134.

28. Zagorskaya EA, Klimovitsky VY, Melnichenko VP, Rodina GP, Semyonov $\mathrm{SN}$. The effect of low frequency electromagnetic fields on physiological systems: a review. Kosm Biol Aviakosm Med 1990;24:3-11.

29. Forgács Z, Thuróczy G, Paksy K, Szabó LD. Effect of sinusoidal $50 \mathrm{~Hz}$ magnetic field on the testosterone production of mouse primary Leydig cell culture. Bioelectromagnetics 1998;19(7):42 9-431 $10.1002 /(\mathrm{SICl}) 1521$ 186X(1998) 19:7<429::AID-

BEM4>3.0.CO;2-3.

30.Burchard JF, Nguyen DH, Block E. Progesterone concentrations during estrous cycle of dairy cows exposed to electric and magnetic fields. Bioelectromagnetics 1998;19(7):438443 $10.1002 /(\mathrm{SICl}) 1521-$ 186X(1998) 19:7<438::AID-

BEM6>3.0.CO;2-2.

31. Feria-Velasco A, Castillo-Medina S, Verdugo-Díaz L, Castellanos E, OrozcoSuárez S, Sánchez-Gómez C, et al. Neuronal differentiation of chromaffin cells in vitro, induced by extremely low frequency magnetic fields or nerve growth factor: a histological and ultrastructural comparative study. J Neurosci Res 1998. Sep;53(5):569-582 10.1002/(SICI)10974547(19980901)53:5<569::AIDJNR7>3.0.CO;2-7.

32.Uscebrka G, Zikic D, Matavulj M, Rajkovic $\mathrm{V}$, Gledic D. Electromagnetic field effects on the morphometrical characteristics of rat adrenal glands. In: Bersani, F. (Ed.), Electricity and Magnetism in Biology and Medicine. Kluwer Academic/Plenum Publishers, New York, pp. 485-488, 1999.

33. Matavulj M, Rajkovic V, Uscebrka G, Lukac T, Stevanovic D, Lazetic B. Studies on the possible endocrinological effects of an 50 $\mathrm{Hz}$ electromagnetic field. Centr. Europ. J. Occup. Environ. Med 2000;6:183-188.

34.Friedhelm, H; (2002) "GSM and UMTS, the Creation of Global Mobile Communications", John Wiley and Sons, Inc., NY. 